For the limiting value $\mathrm{I}=5 \pi / 8$ (two points abaft the beam) the relative speed has this remarkable value:

$$
D=\frac{V_{N}}{\cos \frac{\pi}{8}} \cos \left(g+\frac{\pi}{8}\right)
$$

the equation for the circle, for which the ship's attitude is constant at $5 \pi / 8$. This circle, and the values of $D$, can be calculated in advance for the different bearings and for any given speed of the ship.

In consequence, a comparison of the relative speed (measured on the radar) with this discriminating value $D$, will tell us whether the ship is crossing or overtaking

$$
\begin{aligned}
& V_{R 1}>D=\text { crossing } \\
& V_{R 2}<D=\text { overtaking }
\end{aligned}
$$

Measuring $V_{R}$ is simply a matter of measuring a length on the screen, a simple procedure and one to which the instrument lends itself readily. Thus for the pair bearing-aspect (difficult to read on the radar) we substitute the pair bearingdistance (easy to read), and so we can extend to fog the Steering and Sailing Rules that hold good in clear weather: and then we are on familiar ground.

\title{
A Plotting Device for the Radar Observer
}

\author{
from Captain H. J. Sadler
}

To obtain all the available information from radar when visibility is poor, it is widely recognized that plotting is essential. No doubt plotting is carried out whenever possible, but in many merchant ships at sea today the ideal has limitations due to manning difficulties. Where the master has only one officer on the bridge to assist him it is not easy to cope with all bridge duties and carry out plotting in the usual way. To obtain full and accurate information a plotting officer must give his undivided attention to make use of the three known elements, range, bearing and own speed in order to produce the other ship's course, speed and nearest approach and follow up with the change of course and speed that may be required to keep out of the region of collision.

The plotting device depicted here is an attempt to give the radar observer an opportunity to plot the track of approaching ships himself without the use of instruments and without the assistance of a plotting officer. It may be of a convenient size, 14 in. $\times 8$ in., and backed by stiff cardboard so that it can be used without a table.

The principle of the diagram, Fig. I, is to expand the ship's position at the centre of the PPI to a base-line divided into angles on the bow and a perpendicular from the base-line indicating the range up to a convenient distance. The track of a ship's relative approach is plotted direct from the PPI and the diagram assists us to interpret the information that this track can give.

It can be seen that the constant bearing of another ship, when plotted, is a 
straight line perpendicular to and cutting the base-line at a position which depends on the original angle on the bow. $x x^{\prime}$ is the track of a ship sighted 35 degrees on the port bow approaching on a collision course with an unchanging bearing. If the other ship is to pass clear it must develop a curve similar to $A, B$ or $C$ which show an ever increasing change of bearing to pass 1,2 or 3 miles off respectively.

If suitable permanent curves are illustrated on the diagram, they can be used for comparison with plotted curves to show whether tracks of approaching ships are passing clear or entering the region of collision, and help to decide what action is required to avoid danger.

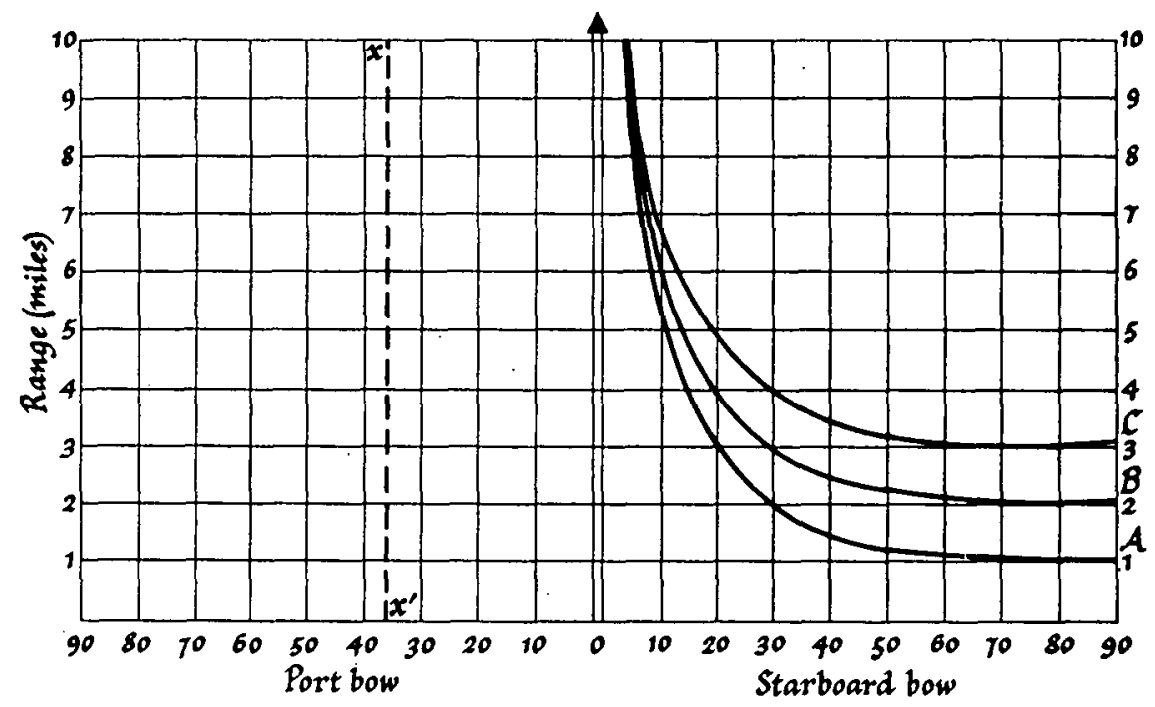

Fig. 1

In Fig. 2 the permanent curves $A, B, C$ and $D$ show the tracks of approaching ships under the following circumstances.

Curve $A$ is the track of a ship sighted at ro miles, 5 degrees on the bow and passing with a nearest approach of $\mathrm{I}$ mile. It is on a parallel course to own ship.

Curve $B$ is the track of a ship sighted at 10 miles, 30 degrees on the bow with a nearest approach of $\mathrm{I}$ mile.

Curve $C$ is the track of a ship sighted at 10 miles, 50 degrees on the bow with a nearest approach of $\mathrm{I}$ mile.

Curve $D$ is the track of a ship sighted at 10 miles, 30 degrees on the bow and crossing own ship's course I mile ahead.

It will be realized that any curve plotted equidistant from Curve $A$ indicates a ship on a parallel course. Any curve that is going to cross the 90-degree bearing line more than three miles off can be considered to indicate the track of a ship on a safe passing course. If it is going to pass I mile off, the approaching ship must be watched with caution, particularly if not on a parallel course. If the curve shows a tendency to approach within one mile we must consider that danger of collision exists.

The plotting diagram uses two elements, bearing and distance. Curve $A$ which shows a ship on a parallel course may be either an approaching or an overtaken ship. When the relative bearing is constant or nearly so, the observer can plot 
at $\mathrm{I}$-mile intervals ( $\mathrm{ra}, \mathrm{b}, \mathrm{c}, \mathrm{d}$, e, in Fig. 2) and note the time interval. We now have a third element to guide us, the speed of relative approach. This can be taken from tabulated data showing speed against the time required to advance I mile (Table I).

Table I. Time to advance one mile

\begin{tabular}{l|c|c|c|c|c|c|c|c|c|c|c|c|c|c}
\hline Min. & $2^{\mathrm{m}}$ & $2^{\mathrm{m}} 30^{\mathrm{s}}$ & $3^{\mathrm{m}}$ & $3^{\mathrm{m}} 30^{\mathrm{s}}$ & $4^{\mathrm{m}}$ & $4^{\mathrm{m}} 30^{3}$ & $5^{\mathrm{m}}$ & $5^{\mathrm{m}} 30 \mathrm{~s}$ & $6 \mathrm{~m}$ & $7^{\mathrm{m}}$ & $8 \mathrm{~m}$ & $9^{\mathrm{m}}$ & $10 \mathrm{~m}$ \\
$\mathrm{Kt}$. & 30 & 24 & 20 & 17.15 & 15.0 & 13.35 & 12 & $10 \cdot 9$ & 10 & 8.6 & 7.5 & $6 \cdot 7$ & 6 \\
\hline
\end{tabular}

To illustrate the situation indicated by the speed of relative approach, the following plotting diagrams show the position at 20 and 70 degrees on the bow when the speed of relative approach is twice own speed $A$ and $B$, when the speed of relative approach and own speed are the same $C$ and $D$, and when the speed of relative approach is half own speed $E$ and $F$ (Fig. 3).

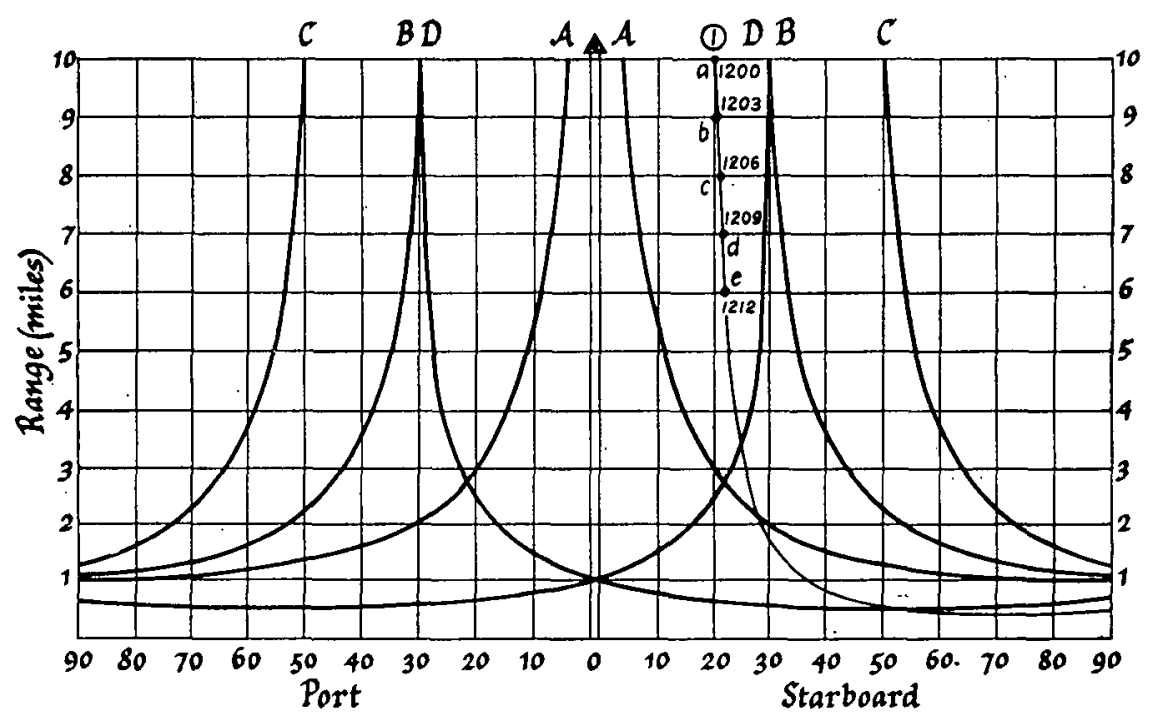

Fig. 2

It can be seen from diagrams (a) and (b) that where the speed of relative approach $O A$ is greater than own speed $O W$, it may be said that the other vessel is approaching. When they are the same, (c) and (d), the other vessel is crossing; and when relative speed is less than own speed, (e) and (f), they are converging. The observer now has more information than he would have by sighting the other vessel in clear weather, and if in each case the bearing remains constant he can decide on appropriate action to avoid collision, either a bold alteration of course or a drastic reduction of speed.

It is not suggested that this system of radar plotting can compare with the precision and mathematical accuracy of the recognized method of plotting which is undoubtedly the most satisfactory when there are sufficient watchkeeping officers to permit one to devote his whole attention to plotting.

In many ships at sea today the master and one watchkeeping officer are the sole 


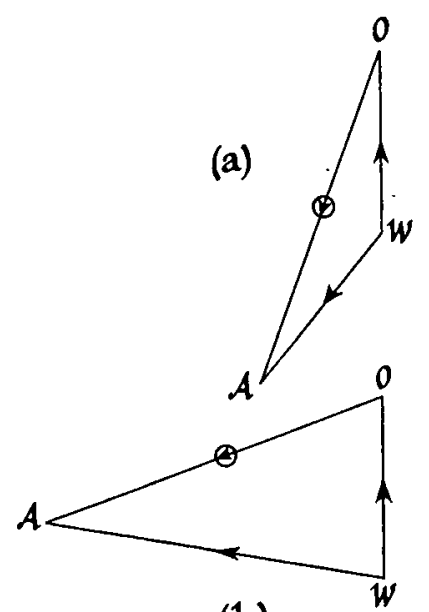

(b) (c)

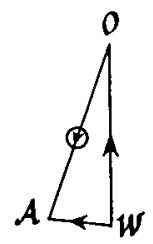

(d) (e)

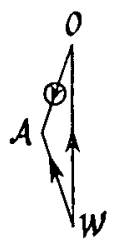

(f)

Fig. 3

occupants of the bridge in foggy weather, and between them they must carry out the manifold duties prescribed by law and the ordinary practice of seamen. It is inevitable that radar plotting and observing are not carried out with maximum efficiency. In such cases this plotting device shows to best advantage and can be used by the observer who, as a practical and experienced navigator, can interpret the information given and decide on the appropriate action to avoid collision.

In the ordinary course of general trading on the regular shipping routes of the world, the great majority of vessels sighted will be on or near parallel courses and most of them will pass at a safe distance. In such cases only the plotting of bearing and distance is required to show that the ship will pass clear. When the occasional ship is found to be approaching on or near a collision course it can be given full attention, and a decision quickly made as to the action required to keep out of the region of collision, probably by a bold alteration of course.

\title{
Navigation Using the Transit of an Artificial Satellite
}

\author{
from D. H. Shinn \\ (Research Division, Marconi's W/T Co.)
}

F. G. SMITH describes (this Journal, 13, 109) a system for determining position from a single observation, probably lasting for a time of the order of a few minutes, of radio transmissions from an artificial Earth satellite. There are in this system two engineering difficulties which I think Dr. Smith has underestimated; these are the frequency stability and the power required. In order to establish these requirements it is necessary to consider in some detail how Dr. Smith's system would work. 